\title{
Novel swellable polymer of orchidaceae family for gastroretentive drug delivery of famotidine
}

This article was published in the following Dove Press journal:

Drug Design, Development and Therapy

9 September 2014

Number of times this article has been viewed

\author{
Mahboubeh Razavi' \\ Shaik Nyamathulla ${ }^{1,2}$ \\ Hamed Karimian' \\ Mohamed Ibrahim \\ Noordin 1,2 \\ 'Department of Pharmacy, Faculty \\ of Medicine, ${ }^{2}$ Center for Natural \\ Products and Drug Discovery, \\ Department of Chemistry, Faculty \\ of Science, University of Malaya, \\ Kuala Lumpur, Malaysia
}

\begin{abstract}
This study aimed to develop hydrophilic, gastroretentive matrix tablets of famotidine with good floating and swelling properties. A novel gastroretentive drug delivery formulation was designed using salep, also known as salepi, a flour obtained from grinding dried palmate tubers of Orchis morio var mascula (Orchidaceae family). The main polysaccharide content of salep is glucomannan, highly soluble in cold and hot water, which forms a viscous solution. Salep was characterized for physicochemical properties, thermal stability, chemical interaction, and surface morphology using X-ray diffraction analysis, differential scanning calorimetry, Fourier transform infrared spectroscopy, and scanning electron microscopy. Ten different formulations (S1-S10) were prepared using famotidine to salep ratios from 1:0.5 to 1:5. Results demonstrated that all formulations were able to sustain the drug release for more than 24 hours. The S5 formulation, with a famotidine to salep ratio of 1:2.5, had the shortest floating lag time of 35 seconds and $100 \%$ drug release within 24 hours. The dissolution data were fitted into popular mathematical models to assess the mechanism of drug release. S5 showed Zero order release ( $R=0.9746$ ) with Higuchi diffusion ( $R=0.9428$ ). We conclude that salep, a novel polymer, can be used in controlled release formulations to sustain release for 24 hours, due to inherent swelling and gelling properties.
\end{abstract}

Keywords: famotidine, floating matrix tablets, gastroretentive drug delivery, orchis, salep

\section{Introduction}

Pharmaceutical excipients are inactive and inert substances of synthetic or natural origin, which are formulated alongside the active ingredient of a drug to help bulk up formulations. ${ }^{1}$ Bulking up allows for convenient and accurate dispensing of a drug substance when producing a dosage form, and this has important implications in the cost and efficacy of any formulation. ${ }^{2}$ Excipients are the largest components of any pharmaceutical formulation. Traditionally, excipients were used in formulations to provide the necessary weight or to mask unpleasant odors or taste. ${ }^{3}$ In modern pharmaceutical technology, there is tremendous interest and need for developing new excipients with multifunctional roles, such as improving drug stability and bioavailability. Improved bioavailability reduces the frequency of drug intake and thereby helps improve patient compliance. ${ }^{4}$

Currently, there are lots of studies geared toward the discovery of natural polymers that can be used as excipients. Natural polymers are obtained in the form of macromolecules. ${ }^{5}$ They are easily available, biodegradable, safe, and nontoxic when used as excipients in drug formulations. ${ }^{6}$ Due to their natural, biocompatible swelling and gelling properties when in contact with aqueous media, natural polymers are suitable for sustaining and controlling release, compared against synthetic polymers. ${ }^{7}$ Natural polymers can be used as binders, diluents, disintegrant agents, colloid-protective, and
Correspondence: Mahboubeh Razavi Department of Pharmacy, Faculty of Medicine, University of Malaya, Kuala Lumpur 50603, Malaysia

Tel +60379673194

Fax +60379674964

Email mahbobehrazavi@gmail.com 
gelling agents in different pharmaceutical dosage forms, and even in cosmetics and papermaking. ${ }^{8}$

Gums and mucilages are kinds of natural polymer with high molecular weight, which can be used as hydrophilic polymers in pharmaceutical technology. ${ }^{9}$ They are condensation polymers of polysaccharides, or complex carbohydrates containing one or more monosaccharide or their derivatives. ${ }^{8}$ The term gum refers to natural plant products made up of hydrocolloid polysaccharides. They are abnormal products of pathological conditions, formed either due to unfavorable growth conditions or due to injury. ${ }^{10}$ Mucilage, on the other hand, refers to physiological products of normal cell activity. Gums and mucilage have similar constituents. ${ }^{11}$

Salep is a hydrocolloid powder obtained from dried roots/ tubers of Orchis morio var mascula, from the Orchidaceae family. ${ }^{12}$ The Orchidaceae is one of the largest families of flowering plants, with 25,000-35,000 species under 750-850 genera. ${ }^{13}$ Palmate tubers of salep mostly grow in Iran and Turkey. There are two forms of salep that grow in Iran: one with branched, or palmate tubers, and the other with rounded, or unbranched tubers. ${ }^{14}$ The palmate tuber is flattened and consists of two to five branches, shown in Figure 1. The most important constituent of salep is mucilage, which accounts for about $48 \%$ of the tuber. ${ }^{15}$ Traditionally, salep was used for its nutritive and demulcent properties. ${ }^{13}$ Currently, it is used as a gelling agent, thickening agent, and stabilizer in ice cream production, since it swells when in contact with water or milk, as well as for its pleasant aroma, smell, and taste. ${ }^{16}$ This natural, neutral polysaccharide is used as a blood sugar manager to relieve pancreas stress, in the prevention of chronic disorders, ${ }^{17}$ in the treatment of constipation, and weight management. ${ }^{18}$ Palmate tubers of salep contain glucomannan (16\%-60\%), starch (2.7\%), nitrogenous substance $(5 \%)$, moisture $(12 \%)$, and ash $(2.4 \%) .{ }^{18}$ The main polysaccharide content of palmate tubers of salep extracts is glucomannan. ${ }^{20}$ Glucomannans consist of D-glycopyranosyl and D-mannopyranosyl residues at a ratio of 1:3.3, its backbone chain consisting of $b(1 \rightarrow 4)$ linked glycosyl and mannosyl residues. ${ }^{19}$

The oral route of administration is therapeutically beneficial over conventional dosage forms, which is why it is more commonly used. The benefits of oral administration include (1) lesser chance of drug toxicity, (2) low cost of therapy, and

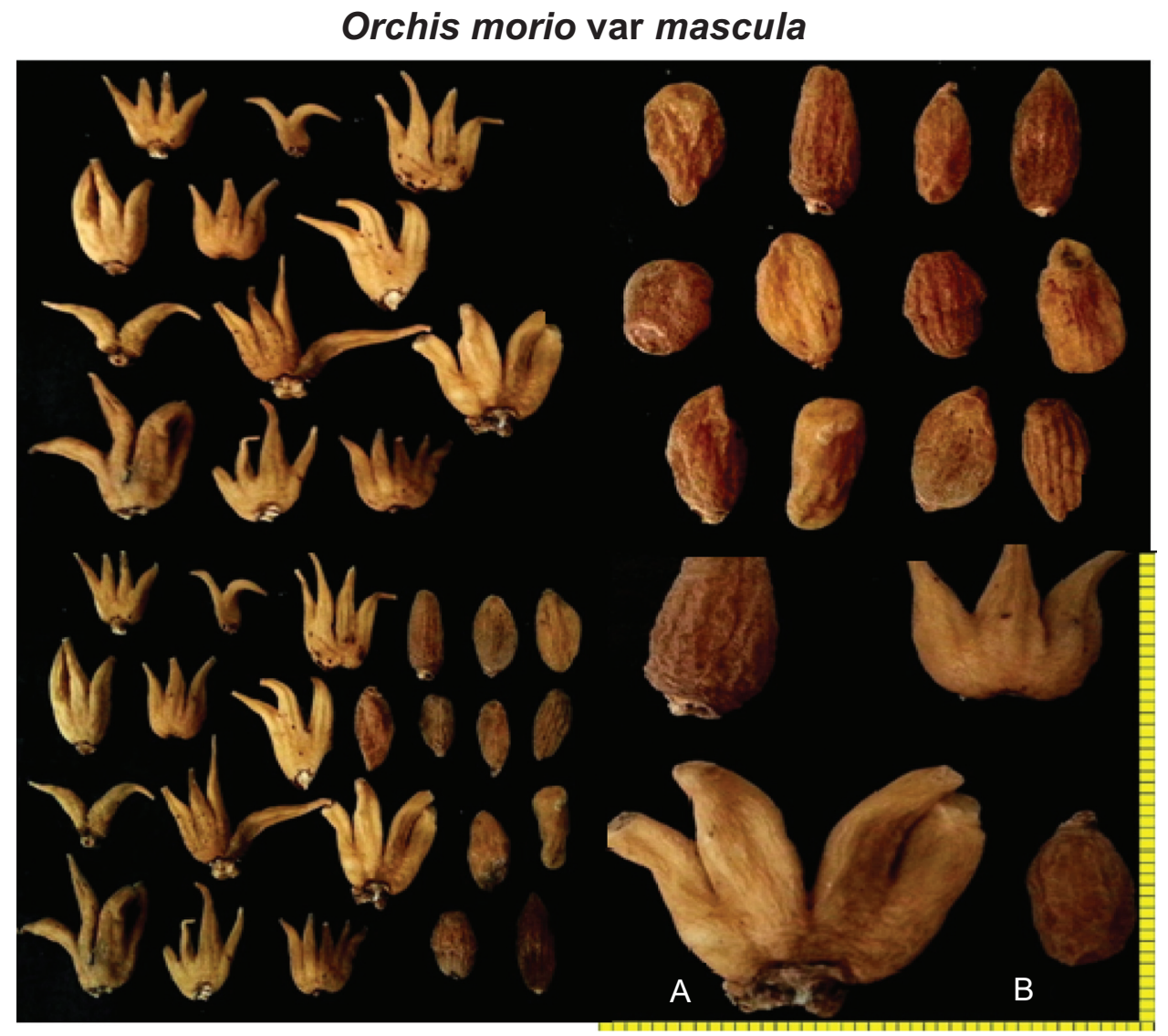

Figure I Palmate (A) and rounded (B) forms of Orchis morio var mascula tubers present in Iran. 
(3) more patient convenience. ${ }^{20}$ Drug bioavailability through the oral route can be affected by factors such as gastric emptying rate, dosage form, gastrointestinal transit time, and drug absorption site. ${ }^{21,22}$ Gastroretentive controlled release technology can improve the bioavailability of drugs that exhibit low solubility at alkaline $\mathrm{pH}$, with instability in the colonic or intestinal region, local activation in the stomach region, and narrow absorption window in the upper part of the gastrointestinal tract. ${ }^{23,24}$

Gastroretentive drug delivery systems can be approached by (1) density-controlled delivery systems, which have two forms: floating and high density. In the floating system, the dosage form floats and remains buoyant at the top of the stomach, while in the high density system, the dosage form remains at the bottom of the stomach; (2) bioadhesive systems, which cause bioadhesion to stomach mucosa; and (3) expandable systems, where the dosage form swells to a large size and remains at the pyloric sphincter. ${ }^{25}$ Floating gastroretentive drug delivery systems have a bulk density lesser than gastric fluid. To achieve this approach, swellable polymers and gas-generating agents are required. ${ }^{26}$ The gas generating agents release $\mathrm{CO}_{2}$ in acidic media; the bubble will pass through the swollen gel's pores and cause tablet floating. Tablets remain floating for a prolonged period of time, without the effect of gastric emptying. ${ }^{27}$

Famotidine is an H2-receptor antagonist; commonly prescribed in gastric ulcers, Zollinger-Ellison syndrome, duodenal ulcers, and gastroesophageal reflux disease. Orally administrated famotidine is incompletely absorbed from the gastrointestinal tract. Low bioavailability $(40 \%-45 \%)$ and short half-life (2.5-4 hours) are the main limitations of the therapeutic effectiveness of famotidine. Due to its short biological half-life, multiple doses are needed to maintain a constant plasma concentration of the drug for good therapeutic response, but increasing the frequency of drug intake can be associated with increased risk of adverse effects and toxic effects. $^{28}$

The objective of the present work was to develop a new gastroretentive formulation, based on floating systems, using a new, natural, and swellable polymer, to improve release of drugs in the stomach and upper gastrointestinal tract. The main objective was to prepare floating matrix tablets with short floating lag time, as well as good floating ability and swelling properties. For the first time, floating, gastroretentive matrix tablets of famotidine were prepared using a novel polymer, to evaluate the effect of salep on floating properties and release characteristics of the dosage form.

\section{Materials and methods} Materials

Famotidine was purchased from Euro Chemo-Pharma Sdn Bhd, Selangor Darul Ehsan, Malaysia, and the palmate tubers of Orchis morio var mascula were procured from the Agricultural Research Center, Boushehr, Iran (voucher number: 4310/266/1). Lactose $\left(\mathrm{C}_{12} \mathrm{H}_{22} \mathrm{O}_{11} \cdot \mathrm{H}_{2} \mathrm{O}, \mathrm{M}=360,31 \mathrm{~g} / \mathrm{mol}\right)$, sodium bicarbonate $\left(\mathrm{NaHCO}_{3}, \mathrm{M}=84.01 \mathrm{~g} / \mathrm{mol}\right)$, cellulose microcrystalline $\left[\left(\mathrm{C}_{6} \mathrm{H}_{10} \mathrm{O}_{5}\right)_{\mathrm{n}}\right]$, potassium chloride $(\mathrm{KCl}$, $\mathrm{M}=74.56 \mathrm{~g} / \mathrm{mol})$, hydrochloric acid 37\% $(\mathrm{HCl}, 36.46 \mathrm{~g} / \mathrm{mol})$ talc, and magnesium stearate were purchased from R\&M Chemicals, Edmonton, Canada.

\section{Collection and preparation of salep}

Palmate tubers were collected from the Agricultural Research Center, Boushehr, Iran. They were dried and then sizereduced using a cutting mill machine (Retsch-Allee, Haan, Germany). The small pieces were then ground into powder using a blender that was run several times to produce a fine powder. The powder was then passed through sieve number 100 and stored in well-closed polypropylene containers in desiccators.

\section{Characterization of salep \\ Determination of bulk and tapped density}

For bulk and tapped density, $3 \mathrm{~g}$ of powder was weighed and placed into a $100 \mathrm{~mL}$ graduated cylinder. The initial unsettled volume of powder was recorded as $\mathrm{V}_{0}$. The cylinder containing the powder was subjected to 300 taps per minute in a tap density tester (Dr Schleuniger Pharmatron, Thun, Switzerland). ${ }^{29}$ After tapping, the volume of the settled powder was read and recorded as $\mathrm{V}_{\mathrm{f}}$. The bulk density (Equation 1) and tapped density (Equation 2) of the powder was calculated using the equations below:

$$
\begin{aligned}
\text { Bulk density } & =\frac{\text { Weight of powder }(\mathrm{W})}{\text { Initial volume of } \operatorname{powder}\left(\mathrm{V}_{0}\right)} \\
\text { Tapped density } & =\frac{\text { Weight of powder }(\mathrm{W})}{\text { Volume of tapped } \operatorname{powder}\left(\mathrm{V}_{\mathrm{f}}\right)}
\end{aligned}
$$

\section{Carr's index and Hausner ratio}

Carr's index and Hausner ratio are both parameters of the flow properties of powders. Carr's index was used to show the relationship between the bulk density and tapped density of the powder, by using the equation below. ${ }^{30}$ The Carr's index value for salep was determined by measuring the initial volume and the tapped volume of a powder of 
known weight after subjecting it to 300 times of tapping (Equation 3).

$$
\text { Carr's index }=\frac{\text { Tapped density }- \text { Bulk density }}{\text { Tapped density }} \times 100
$$

Hausner ratio was calculated by using the equation below (Equation 4). The flow ability of the powder was determined by the results of the Carr's index.

$$
\text { Hausner ratio }=\frac{\rho t}{\rho b}
$$

where $\rho b=$ bulk density and $\rho t=$ tapped density.

\section{Moisture content of salep and granules}

Powder from palmate tubers and granules were analyzed for moisture content, using the HR73 and HG53 moisture analyzers (Mettler Toledo, Greifensee, Switzerland). In this process, a sample ( $2 \mathrm{~g})$ is weighed before and after drying, and a difference in mass between these two is calculated.

\section{$\mathrm{pH}$ determination of salep}

About $0.5 \% \mathrm{w} / \mathrm{v}$ of the sample was prepared using distilled water and $\mathrm{pH}$ was determined using a calibrated $\mathrm{pH}$ meter (SevenEasy ${ }^{\mathrm{TM}}$ S20; Mettler Toledo).

\section{Swelling study of salep}

The swelling ability of salep was measured using a method adopted from Murali Mohan Babu et al (Equation 5). ${ }^{31}$ Salep powder was immersed in three different swelling solutions: water, $\mathrm{pH} 1.2,4.5,6.8$, and 7.4. The sample was gently mixed with the solution, and the initial level of the sample recorded. The samples were then allowed to swell for 24 hours. During the 24 hours, the solution was gently mixed using a glass rod, to ensure contact of the salep power with the medium. The final level of the sample after 24 hours was recorded, and the swelling index calculated using the equation below (Equation 5).

$$
\begin{aligned}
& \text { Height of the swollen gum }- \\
& \text { SI }=\frac{\text { Initial height of the gum powder }}{\text { Initial height of gum powder }} \times 100
\end{aligned}
$$

\section{Viscosity of salep}

The viscosity was determined with a Brookfield Ultra programmable rheometer (DV-III Ultra, Brookfield Engineering Laboratory Inc., Middleboro, MA, USA). The spindle used in this study was chosen based on the viscosity of the sample.
Hence, spindle CP-52 was used for $0.5 \%, 1 \%$, and $1.5 \%$ of salep. Samples were prepared with distilled water and allowed to swell for 24 hours prior to the study. The viscosity of the prepared concentrations was evaluated with an increment of $5 \mathrm{rpm}$ of cone speed until $100 \mathrm{rpm}$, at $25^{\circ} \mathrm{C}$, and by using Rheocalc software. The result of viscosity changes in response to shear rate was determined.

\section{Scanning electron microscopy of salep}

The external morphology (texture), chemical composition, crystalline structure and orientation of materials making up the tuber powder were characterized using field emission scanning electron microscopy (Quanta 450 FEG; FEITM, Hillsboro, OR, USA). The Quanta 450 was used to image and analyze surface topography, collect backscattered electron images, and characterize and determine the sample's elemental composition through X-ray detection, using a silicon drift detector with energy-dispersive X-ray spectroscopy.

\section{Preparation of matrix tablets of famotidine using salep}

All the ingredients used for making the matrix tablets (see Table 1) were sieved using mesh number 100, and quantities required were accurately weighed using an analytical balance (NewClassic MS-S/MS-L; Mettler-Toledo). Different formulations of matrix tablets of famotidine were prepared using the wet granulation method. ${ }^{32}$ The composition of each formulation is shown in Table 1. All ingredients, except the lubricant, were mixed using the geometrical dilution method. The powder mixture was then granulated using $2 \% \mathrm{w} / \mathrm{v}$ of salep as a binder solution. The wet granules were then passed through sieve number 10 and dried at $50^{\circ} \mathrm{C}$ until constant moisture level was achieved. The dried granules were then sieved again, to resize, using sieve number 18. Premixed magnesium stearate and talc were used as lubricants. The lubricant was added into the dry granules and mixed well. The lubricated granules were then compressed into tablets using a single-punch tablet machine (MTCM-I Manual Tablet Compaction Machine; GlobePharma, New Brunswick, NJ, USA) which has a $10 \mathrm{~mm}$ round, flat-faced punch, at compression pressure of 2,200 N.

\section{Physical evaluation of prepared matrix tablets}

Tablets prepared from all the different formulations were evaluated for hardness, weight variation, friability, floating time, floating lag time, and drug content uniformity. 
Table I Composition of floating matrix tablet formulations of famotidine, prepared using salep as a gel forming agent

\begin{tabular}{|c|c|c|c|c|c|c|c|}
\hline \multirow[t]{2}{*}{ Formulation } & \multicolumn{7}{|c|}{ Ingredients (mg/tablet) } \\
\hline & Famotidine & Salep & MCC & $\mathrm{NaHCO}_{3}$ & Mg stearate & Talc & Total weight \\
\hline SI & 40 & 20 & 100 & 100 & 5 & 5 & 270 \\
\hline S2 & 40 & 40 & 100 & 100 & 5 & 5 & 290 \\
\hline S3 & 40 & 60 & 100 & 100 & 5 & 5 & 310 \\
\hline S4 & 40 & 80 & 100 & 100 & 5 & 5 & 330 \\
\hline S5 & 40 & 100 & 100 & 100 & 5 & 5 & 350 \\
\hline S6 & 40 & 120 & 100 & 100 & 5 & 5 & 370 \\
\hline S7 & 40 & 140 & 100 & 100 & 5 & 5 & 390 \\
\hline S8 & 40 & 160 & 100 & 100 & 5 & 5 & 410 \\
\hline S9 & 40 & 180 & 100 & 100 & 5 & 5 & 430 \\
\hline SIO & 40 & 200 & 100 & 100 & 5 & 5 & 450 \\
\hline
\end{tabular}

Abbreviation: MCC, microcrystalline cellulose.

\section{Weight variation of prepared tablets}

Twenty tablets were selected randomly and weighed individually using an analytical balance (MS-S/MS-L), and then the average of the 20 tablets was calculated. Individual weights were compared with the average weight, in order to determine the weight variation.

\section{Thickness, diameter and hardness of prepared tablets} Ten tablets were chosen randomly from each formulation. The diameter and thickness of each tablet were measured using a tablet hardness tester (6D; Dr Schleuniger Pharmaton). The results were recorded and compared among the different formulations.

Ten tablets were chosen randomly from each formulation. Hardness of these tablets was determined using the tablet hardness tester. The result was recorded and compared among the different formulations.

\section{Friability of prepared tablets}

All the formulations of the prepared tablets were tested for friability. Tablets equal to $6 \mathrm{~g}$ were weighed, and recorded as W1. The friability of the tablets was measured using a Friability tester (Roche Tar 10; Erweka GbmH, Ensenstam, Germany) with 25 rotations per minute for 4 minutes. After 100 rotations, the tablets were de-dusted and reweighed. The weight was recorded as W2..$^{33}$ The acceptable range of the friability test is less than $1 \%$. Friability was calculated using the formula:

$$
\text { Friability }=\frac{\mathrm{W} 1-\mathrm{W} 2}{\mathrm{~W} 1} \times 100 \%
$$

\section{Drug content of prepared tablets}

Three tablets from each formulation were crushed into powder form and a weight equivalent to $100 \mathrm{mg}$ of the crushed tablet was weighed, transferred to a volumetric flask, and diluted to $100 \mathrm{~mL}$ with distilled water. The solution was filtered and absorbance measured at $265 \mathrm{~nm}$ using an ultra-violent spectrophotometer (Lambda 35; PerkinElmer, Waltham, MA, USA).

\section{Floating lag time and total floating time}

The duration of time taken by a tablet to float on the surface of the medium is called the floating lag time (FLT) and duration of time taken by a tablet to remain constantly on the surface of the medium is called the total floating time (TFT). These two are used to measure buoyancy. Randomly selected tablets from each formulation were kept in a beaker containing $500 \mathrm{~mL}$ of simulated gastric fluid at $\mathrm{pH} \mathrm{1.2,} \mathrm{and}$ the FLT and TFT were determined. ${ }^{34}$

\section{Differential scanning calorimetry} of the optimum formulation (S5)

A small amount of famotidine, salep, and powder of the crushed tablet of S5 formulation were loaded into an aluminium pan, followed by crimping to seal the pan. The sample was analyzed using a differential scanning calorimeter (DSC 6; Perkin Elmer) with a heating rate of $10^{\circ} \mathrm{C} / \mathrm{min}$ and nitrogen purge gas at a flow rate of $20 \mathrm{~mL} / \mathrm{min}$.

\section{Fourier transform infrared spectroscopy of optimum formulation (S5)}

Small amounts of famotidine, salep, and powder of the crushed tablet of S5 formulation were mixed with potassium bromide and separately made into small and thin pellets. The pellets were analyzed using a Fourier transform infrared spectrophotometer (Nicolet ${ }^{\mathrm{TM}}$ IS $^{\mathrm{TM}}$ 10; Thermo Fisher Scientific, Waltham, MA, USA).

\section{X-ray diffraction analysis of optimum formulation (S5)}

The X-ray diffraction spectra of the optimum formulation were analyzed using an X-ray diffraction analysis (XRD) 
diffract meter (BTX; inXitu Inc., Mountain View, CA, USA). Dry samples were pressed into pellets and their diffractograms were recorded using $\mathrm{Cu}-\mathrm{K} \alpha$ radiation (40 kV, $60 \mathrm{~mA}$ ). Diffractograms were run at a scanning speed of $2 \% \mathrm{~min}$ and a chart speed of $2 \% / 2 \mathrm{~cm}$ per $2 \theta$ for pure famotidine, salep, and powder of the crushed tablet of formulation S5.

\section{Microbial load of the salep and formulation}

The microbial load was analyzed in salep and formulation based on the method adopted from The United States Pharmacopeia (USP) 30-National Formulary 25. ${ }^{35}$ Briefly, fresh samples of salep and formulation were made after a series of dilutions, to get a dispersion of $1 \mu \mathrm{g} / \mathrm{mL}$. About $50 \mu \mathrm{L}$ of the dispersion was poured into agar plates; the plates were kept in an incubator at $37^{\circ} \mathrm{C}$ for 24 hours. The total number of colonies formed after the incubation period was counted. A fungal count of the samples was also done by the plate count method, using potato dextrose agar medium incubated at $30^{\circ} \mathrm{C}$ for 48 hours.

\section{In vitro drug release study}

In-vitro release studies were carried out using the USP-II dissolution test apparatus (Copley Scientific Limited, Nottingham, UK). A dissolution medium of $900 \mathrm{~mL}$ of $0.1 \mathrm{~N} \mathrm{HCl}$ ( $\mathrm{pH} 1.2$ ) was used in the dissolution basket and maintained at a temperature of $37^{\circ} \mathrm{C} \pm 0.5^{\circ} \mathrm{C}$. Paddle speed was maintained at $50 \mathrm{rpm}$. Five millilitre samples were withdrawn at predetermined time intervals for 24 hours, and $5 \mathrm{~mL}$ of the fresh medium, kept at the same temperature, was replaced. The samples were diluted and analyzed at $265 \mathrm{~nm}$ by using the ultraviolet spectrophotometer. The dissolution profiles were obtained by plotting the cumulative percentage of drug released on the y-axis and time (in hours) on the $\mathrm{x}$-axis. ${ }^{30}$

\section{Drug release kinetics}

The in vitro dissolution test data were fitted into mathematical models representing (i) Zero order, (ii) First order, (iii) Higuchi's, and (iv) Hixson-Crowell equations, in order to determine the release mechanism and the order of drug release.

\section{Zero order}

As the cumulative amount of drug released versus time, it describes the concentration-independent drug release rate from the formulation (Equation 6),

$$
\mathrm{C}=\mathrm{k}_{\mathrm{o}} \mathrm{t}
$$

where $\mathrm{k}_{\mathrm{o}}$ is the zero order rate constant, expressed in units of concentration/hour.

\section{First order}

As log cumulative percent drug remaining versus time, it describes a concentration-dependent drug release from the system (Equation 7),

$$
\log C=\log C_{0}-k t / 2.303
$$

where $\mathrm{C}_{0}$ is the initial concentration of drug and $\mathrm{k}$ is the first order constant. ${ }^{36}$

\section{Higuchi's model}

As a cumulative percentage of drug released versus square root of time, it describes the release of drug based on Fickian diffusion, as a square root of time-dependent process from swellable, insoluble matrix (Equation 8),

$$
\mathrm{Q}=\mathrm{kt}^{1 / 2}
$$

where $\mathrm{k}$ is the constant reflecting the design variables of the system.

\section{Hixson-Crowell cube root law}

As the cube root of percentage drug remaining versus time, it is correlated with the release from systems with polymer erosion/dissolution, resulting in a change in surface area and diameter of particles or tablets (Equation 9),

$$
\mathrm{Q}_{0}{ }^{1 / 3}-\mathrm{Q}_{\mathrm{t}}^{1 / 3}=\mathrm{k}_{\mathrm{HC}} \mathrm{t}
$$

where $Q_{t}$ is the amount of drug released at time $t, Q_{0}$ is the initial amount of the drug in the tablets, and $\mathrm{k}_{\mathrm{HC}}$ is the rate constant for the Hixson-Crowell rate equation. ${ }^{37}$

\section{Results and discussion}

Natural polymers are often preferred to synthetic materials, due to their nontoxicity, low cost, and free availability. Various kinds of natural gums are used in the food industry and are regarded as safe for human consumption. It should be essential to replace certain old materials, due to diverse new molecules' incompatibility, but still these materials compete successfully today, after almost a century of efforts to replace them. It is the usual balance of economics and performance that determines the commercial realities. Natural polymers have been modified to overcome certain drawbacks, like uncontrolled rate of hydration, thickening, drop in viscosity on storage, and microbial contamination. However, the use 
of natural hydrophilic matrices is often questionable, due to changes in their properties, like viscosity, swelling, and uniformity. This is largely due to variation in the source, time of collection, purity, and microbial contamination. Hence, proper characterization can assure their use as excipients. Salep, being a natural polymer with diversity in its characters, needs an in-depth characterization to ensure its robustness and consistency.

\section{Characterization of salep}

The release rate of a drug depends on the physicochemical properties, morphology, size of particles, thermodynamic compatibility, and compatibility of polymers and other ingredients. Therefore, before the preparation of matrix tablets, palmate tubers of salep were analyzed for their physicochemical characteristics, and the results are shown in Table 2.

\section{Determination of bulk and tapped densities}

The bulk and tapped density of salep powders were measured to be $0.666 \mathrm{~g} / \mathrm{mL}$ and $0.75 \mathrm{~g} / \mathrm{mL}$, respectively (Table 2). The density of powders is used to specify their flowability. Optimum flowability of powders is a critical factor in the manufacturing process of solid dosage forms. Generally, the flowability of powder increases with an increase in particle size, and there appears to be a critical size range above which flowability does not show any improvement. Bulk density refers to the mass of powder that can be packed into a specific volume. The tapped and bulk densities are obtained by tapping the container holding the sample. The powder particles are forced to jump and to lose contact with each other for

Table 2 Physicochemical characterization of salep and granules

\begin{tabular}{ll}
\hline Characterization parameters & Salep $\pm \mathbf{S D}(\mathbf{n}=\mathbf{3})$ \\
\hline Tap density $(\mathrm{g} / \mathrm{mL})$ of powder & $0.75 \pm 0.9$ \\
Tap density $(\mathrm{g} / \mathrm{mL})$ of granules & $328.09 \pm 0.1$ \\
Bulk density $(\mathrm{g} / \mathrm{mL})$ of powder & $0.666 \pm 0.86$ \\
Bulk density $(\mathrm{g} / \mathrm{mL})$ of granules & $251.79 \pm 1.2$ \\
Hausner ratio of powder & $1.12 \pm 0.3$ \\
Hausner ratio of granules & $0.76 \pm 0.088$ \\
Carr's index $(\%)$ of powder & $12 \pm 1.03$ \\
Carr's index $(\%)$ of granules & $23.43 \pm 1.5$ \\
Moisture content $(\%)$ of powder & $2.191 \pm 0.9$ \\
Moisture content $(\%)$ of granules & $3.251 \pm 1.5$ \\
pH & $4.18 \pm 0.78$ \\
Swelling index at $\mathrm{pH} 7.4$ & $2,150 \pm 1.97$ \\
Swelling index at $\mathrm{pH} 7$ & $4,900 \pm 0.9$ \\
Swelling index at $\mathrm{pH} 6.8$ & $1,150 \pm 1.07$ \\
Swelling index at $\mathrm{pH} \mathrm{I} .2$ & $4,650 \pm 0.98$ \\
Swelling index at $\mathrm{pH} 4.5$ & $5,900 \pm 0.85$ \\
\hline
\end{tabular}

Abbreviation: SD, standard deviation. a moment while tapping. When there is reduced friction between the particles, the particles rearrange and, thus, tapping results in improved packing conditions. ${ }^{38}$

\section{Carr's index and Hausner ratio}

Carr's index and Hausner ratio were found to be $12 \%$ and 1.12, respectively. The Carr's index and Hausner ratio are widely used in characterising flow properties of pharmaceutical excipients. A Carr's index value of $12 \%-16 \%$ and a Hausner ratio of less than 1.25 indicated good flowability of the salep powder (Table 2).

\section{Moisture content of salep and granules}

Our results show that salep contains about $2.191 \% \pm 0.9 \%$ moisture (Table 2). Exposure to high temperature and humidity results in a change of powder state, affecting the release profile. The stability of a powder depends on its moisture content. The presence of moisture not only promotes hydrolysis, but also favors microbial growth and subsequent decomposition of the materials. ${ }^{39}$

\section{$\mathrm{pH}$ determination}

The $\mathrm{pH}$ of salep was found to be $4.18 \pm 0.78$ (Table 2 ). The acidic property of salep might be due to ferulic acid and fatty acid groups present in its structure.

\section{Swelling study of salep}

Swelling studies were performed to determine the swelling ability of salep powder. Results are presented in Table 2. The highest swelling index of salep was 5,900 \pm 0.85 , which was observed at $\mathrm{pH} 4.5$, followed by $4,900 \pm 0.9$ at $\mathrm{pH} 7$, $4,650 \pm 0.98$ at $\mathrm{pH} 1.2,2,150 \pm 1.97$ at $\mathrm{pH} 7.4$, and 1,150 \pm 1.07 at $\mathrm{pH}$ 6.8. The swelling property and gel formation ability of salep have an important role in sustained release behavior. The swelling behavior indicated the rate at which the formulation absorbed water from dissolution media and swelled. The rate of drug release is determined by diffusion through the gel formed as a layer.

\section{Viscosity of salep}

Viscosity of $0.5 \%, 1 \%$, and $1.5 \%$ gel formulations was found to be in the range of 176 centipoise (cP), 1,101.34 cP, and $2,143.15 \mathrm{cP}$, respectively, as shown in Figure 2. Increasing the concentration of the polymer (from $0.5 \%$ to $1.5 \%$, $\mathrm{w} / \mathrm{v}$ ) led to an increased viscosity. The rate of drug release decreased with increased viscosity. A higher-viscosity film forms a stronger barrier, which decreases the amount of water penetrating into the deeper layers of tablet matrix..$^{40}$ 

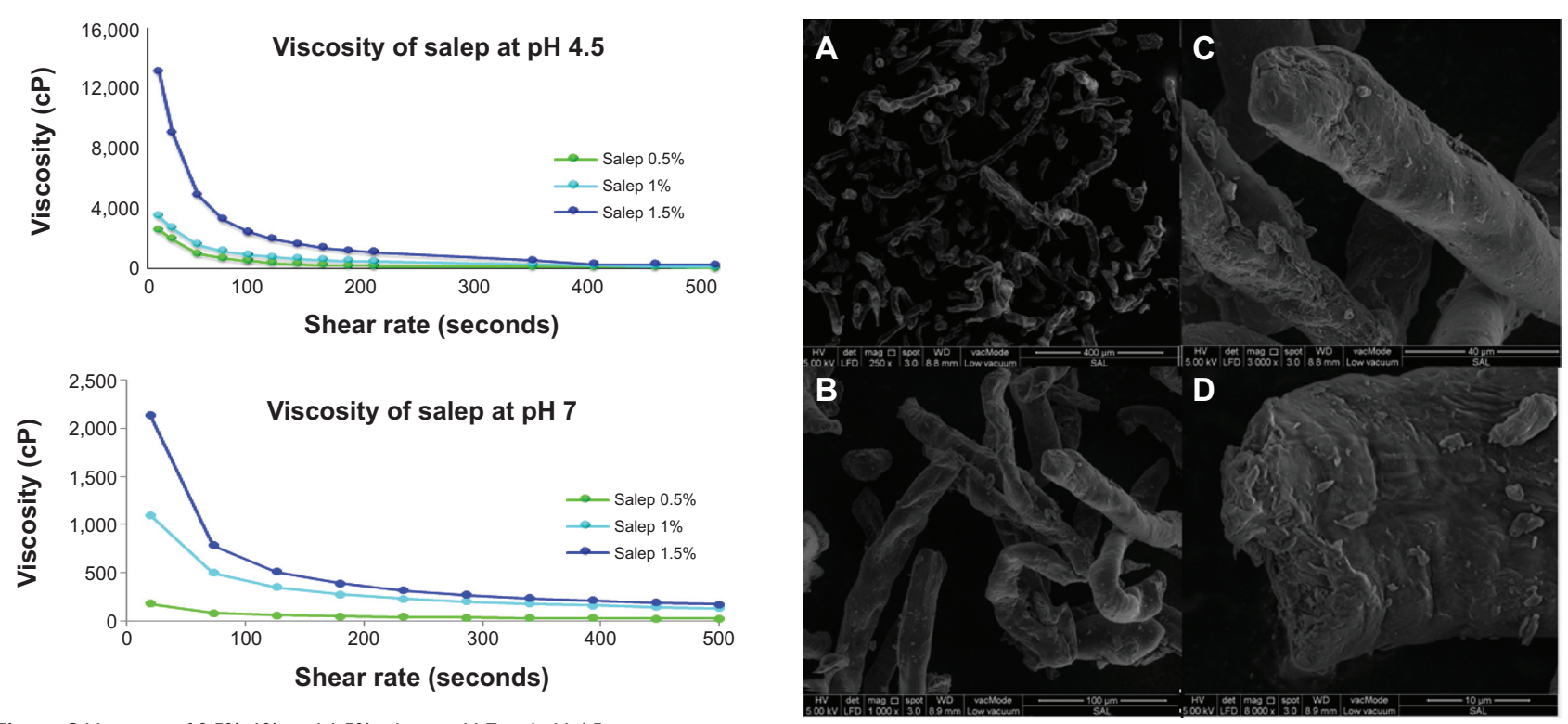

Figure 2 Viscosity of $0.5 \%, 1 \%$, and $1.5 \%$ salep at $\mathrm{pH} 7$ and $\mathrm{pH} 4.5$. Abbreviation: $\mathrm{cP}$, centipoise.

Viscosity is the main parameter to assess the quality of polymers. The applications of any polymer are dependent on its viscosity. For any polymer to be used in slow-release hydrophilic matrix systems, it should possess certain characteristics, like fast hydration of the polymer and a matrix having a high gel strength, and should be stable during the shelf life. Viscosity is partly responsible for such properties. A plot between shear rate and viscosity reveals a typical shear thinning phenomenon of polymers for salep, with non-Newtonian flow.

\section{Scanning electron microscopy of salep}

It is well known that the physicochemical properties and biopharmaceutical behavior of final dosage forms could be affected by the size and the shape of the excipients. The influence of the shape on flow, mixing efficiency, stability, dissolution, and on formulation homogeneity is critical in formulation development. Scanning electron microscopy (SEM) was used to characterize the surface morphology of salep. Irregular rod-shaped particles with roughened surfaces were observed. The SEM photomicrographs showed that salep powder has two irregular sizes of particles, a small and a larger one. However, both have rough surfaces and round, rough edges (Figure 3).

\section{Evaluation of the prepared tablets}

The floating, gastroretentive tablets of famotidine were prepared by a wet granulation technique, using salep, cellulose microcrystalline, lactose, sodium bicarbonate, along

Figure 3 SEM microphotography of salep powder.

Notes: (A) $\times 250$, scale: $400 \mu \mathrm{m}$; (B) $\times 1000$, scale: $100 \mu \mathrm{m}$; (C) $\times 3000$, scale: $40 \mu \mathrm{m}$; (D) $\times 8000$, scale: $10 \mu \mathrm{m}$.

Abbreviation: SEM, scanning electron microscopy.

with magnesium stearate and talc. In the solid dosage form, production by wet granulation, dry granulation, and direct compression are often used. Direct compression is always the first choice of manufacturers, as it reduces overall cost and time during manufacturing. However, wet granulation has certain benefits, like good particle size distribution, good flow of the granules, good uniformity of the dosage forms, and this is also a flexible technique, except for moisturesensitive drugs. In this study, the direct compression method was initially used; the resulting tablets were soft, with a hardness of $38 \pm 1.9 \mathrm{~N}$, and failed to sustain the release up to a desired 24-hour period. Hence, wet granulation was adopted, as it is the second best choice in manufacturing. Physical characterizes of floating tablets were determined, and the results are shown in Table 3 . The physical evaluation of the tablets revealed a uniform thickness and weight for all the tablets. The thickness of all formulation batches ranged from $2.31 \pm 0.14 \mathrm{~mm}$ to $4.13 \pm 0.83 \mathrm{~mm}$. Based on the permitted deviation of $5 \%$ from the mean, for tablets with a total weight of about $250 \mathrm{mg}$ or more, the weight of the S1-S10 formulations were within an acceptable range of 270-450 mg. Based on the USP requirement for tablets with a stated dose of less than $50 \mathrm{mg}$, all the 20 tablets showed a drug content uniformity of between $98.13 \% \pm 2.3 \%$ and $99.91 \% \pm 1.8 \%$. The hardness values between $99-171 \mathrm{~N}$ and low friability values $(<0.35 \%)$ across all formulations indicated that the tablets had sufficient mechanical strength (Table 3). 
Table 3 Physical evaluation of the floating gastroretentive matrix tablets of famotidine, prepared using salep

\begin{tabular}{llllll}
\hline Formulation & Weight variation $\mathbf{( m g )}$ & Hardness $\mathbf{( N )}$ & Thickness $(\mathbf{m m})$ & Diameter $(\mathbf{m m})$ & Friability $(\%)$ \\
\hline S1 & $270.98 \pm 1.13$ & $171 \pm 4.00$ & $2.31 \pm 0.14$ & $9.88 \pm 0.01$ & 0.49 \\
S2 & $290.4 \pm 0.91$ & $149 \pm 4.73$ & $2.51 \pm 0.01$ & $9.88 \pm 0.01$ & 0.34 \\
S3 & $310.9 \pm 1.06$ & $124 \pm 5.77$ & $2.7 \pm 0.11$ & $9.87 \pm 0.02$ & 0.28 \\
S4 & $118 \pm 7.55$ & $2.91 \pm 0.03$ & $9.88 \pm 0.02$ & 0.44 \\
S5 & $329.8 \pm 1.02$ & $99 \pm 3.61$ & $3.44 \pm 0.03$ & $9.88 \pm 0.01$ & 0.38 \\
S6 & $351 \pm 1.06$ & $118 \pm 5.09$ & $3.53 \pm 0.21$ & $9.87 \pm 0.02$ & 0.39 \\
S7 & $370.8 \pm 0.81$ & $112 \pm 4.54$ & $3.77 \pm 0.09$ & $9.87 \pm 0.04$ & 0.24 \\
S8 & $390.96 \pm 1.09$ & $109 \pm 4.99$ & $3.91 \pm 0.34$ & $9.88 \pm 0.01$ & 0.28 \\
S9 & $409.2 \pm 1.08$ & $108 \pm 5.45$ & $3.98 \pm 0.09$ & $9.88 \pm 0.02$ & 0.43 \\
S10 & $430.57 \pm 0.98$ & $102 \pm 6.08$ & $4.13 \pm 0.83$ & $9.89 \pm 0.01$ & 0.39 \\
\hline
\end{tabular}

Note: Results except for friability are shown as mean \pm standard deviation.

\section{Floating lag time and total floating time of prepared matrix tablets}

Sodium bicarbonate was used as a gas-generating agent in preparation of floating matrix tablets. The floating capacities (FLT and TFT) for ten prepared formulations were examined, and the results are shown in Figure 4. The results show that all the tablets prepared and compressed at 2,200 $\mathrm{N}$ were able to float within 17 minutes. It was proved in a previous study that sodium bicarbonate can affect the floating lag time by forming gas bubbles after reacting with the acidic medium. The ability of the matrix layer to trap gas bubbles inside the gel matrix plays an important role in floating lag time, by prolonging floating duration. ${ }^{41}$ Adding sodium bicarbonate could improve the floating capabilities for all ratios of salep to famotidine, with different viscosity grades. However, improving the floating duration was more significant for those formulations that were made using higher viscosity grades of salep, to certain limits.

These results indicate that FLT depended on the salep concentration, as an equal amount of sodium bicarbonate was used in all formulations. The S5 formulation, with a famotidine:salep ratio of 1:1.5, had the shortest FLT. An increase in salep concentration led to increased FLT. This could be due to the high molecular weight of salep, which may interfere with FLT. Formulation S1 disintegrated before floating. S2 partly disintegrated, and the remaining part floated within a few seconds.

Except for the S1 and S2 formulations, the rest of the formulations had long floating durations (more than 24 hours). This might be due to the high viscosity of salep used to prepare these formulations, which could have developed a strong gel matrix. The air bubbles trapped inside the matrix

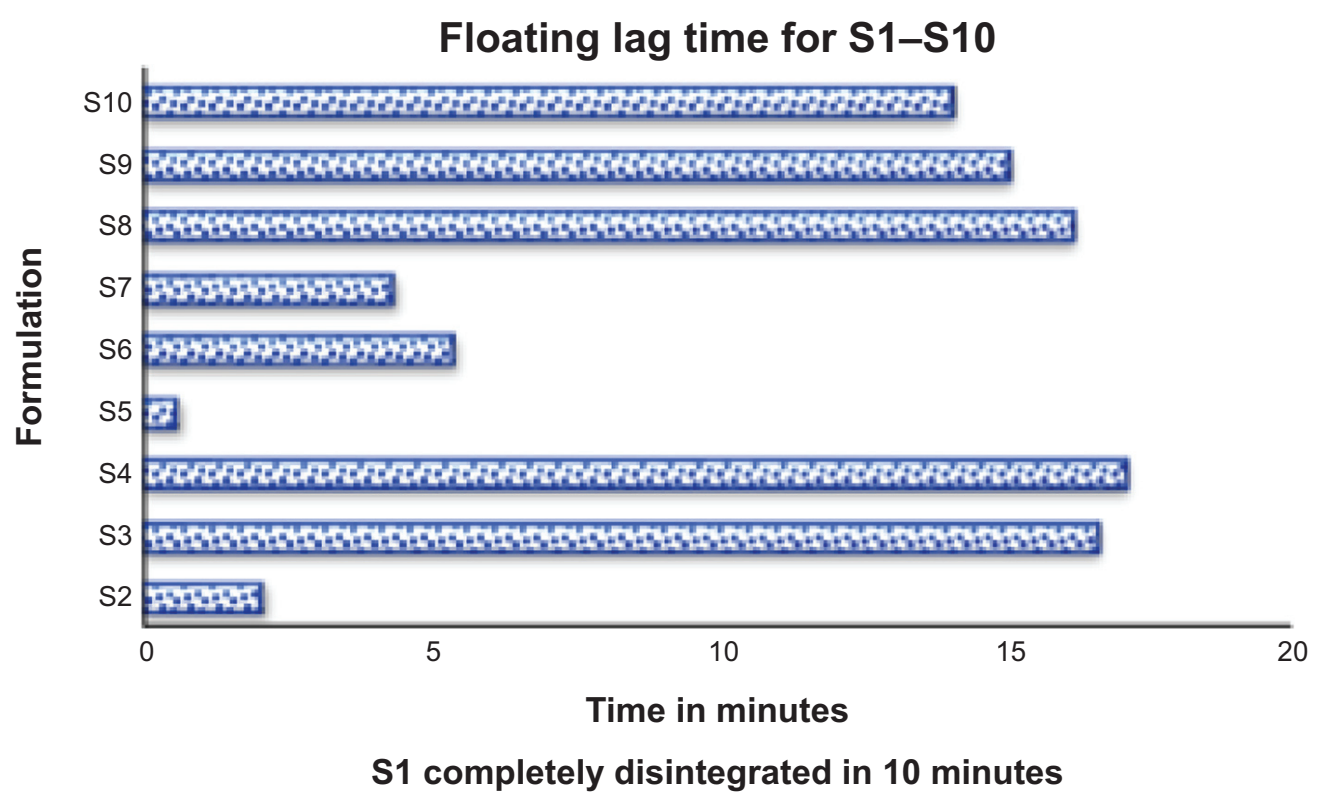

Figure 4 Floating lag time of SI-SIO formulations.

Notes: S1 disintegrated in 10 minutes, S2 disintegrated partially, but S3-S10 batches remained well-swelled and intact for more than 24 hours. 
layer maintain buoyancy for a longer time, with a slow dissolving rate that maintains integrity for floating. ${ }^{42}$ The complete disintegration of S1 and partial disintegration of S2 might be because of the low concentration of salep used in the formulation, and the inability to induce enough strong swelling hydrogel of the matrix layer to maintain the floating.

\section{Differential scanning calorimetry of salep}

A differential scanning calorimetry (DSC) thermogram of pure famotidine showed a sharp peak as the drug melted at $167.39^{\circ} \mathrm{C}$, indicating that the drug is an anhydrous crystalline molecule of high purity. Meanwhile, a broad peak was observed at $116.55^{\circ} \mathrm{C}$ from the DSC thermogram of pure salep, indicating that the melting transition of this powder occurred at this temperature. The melting endotherm of salep was a broad (instead of a sharp) peak, indicating a polymer with components of multiple thermal characteristics. From the DSC thermograms of crushed tablets, peaks corresponding to the melting endotherm of pure famotidine and pure salep were shown. There was no significant change in the melting point of the drug and powder in crushed tablets, compared against the pure drug and polymer, and no other appreciable peak was observed (Figure 5). This indicated that there was no interaction between famotidine and the polymers. In other words, drug and polymers were compatible.
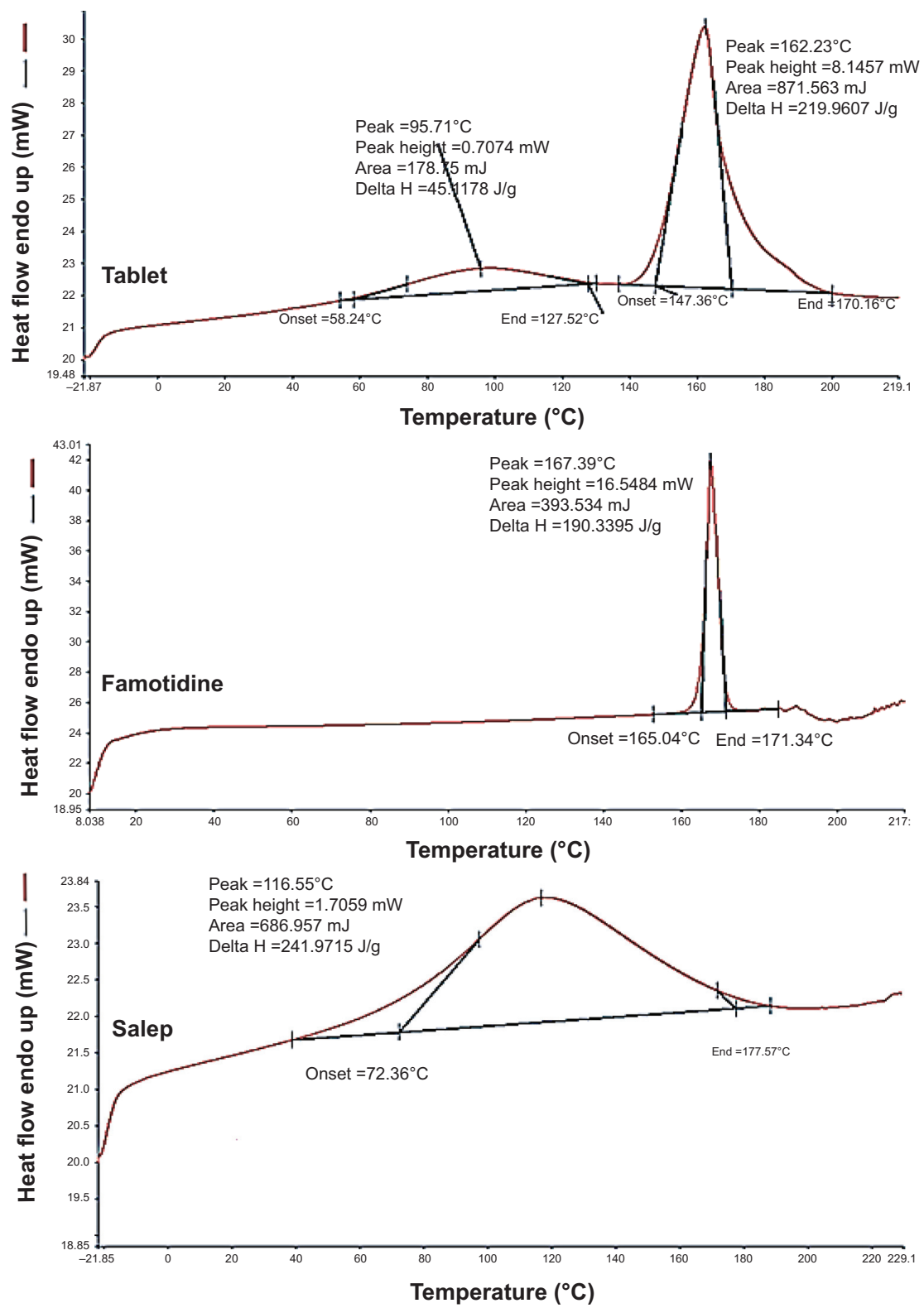

Figure 5 Differential scanning calorimetry thermogram of pure famotidine, pure salep powder, and crushed tablet of optimum formulation (S5). 


\section{Fourier transform infrared spectroscopy of salep}

To characterize salep from fourier transform infrared spectroscopy (FTIR) spectra, the wavelength range of $950 \mathrm{~cm}^{-1}$ to $1,200 \mathrm{~cm}^{-1}$ is considered a fingerprint region, as it allows for the identification of major functional groups in polysaccharides, such as $\mathrm{C}-\mathrm{O}$ stretch, where peaks were obtained at $1,023.52 \mathrm{~cm}^{-1}, 1,062.96 \mathrm{~cm}^{-1}$, and $1,146.60 \mathrm{~cm}^{-1}$. Other than fingerprint regions, pure salep exhibited a few peaks due to the presence of functional groups, which were obtained at $3,355.39 \mathrm{~cm}^{-1}, 2,927.22 \mathrm{~cm}^{-1}, 1,645.36 \mathrm{~cm}^{-1}$, and $1,371.37$ $\mathrm{cm}^{-1}$. For pure famotidine, peaks were detected at 3376.09 $\mathrm{cm}^{-1}, 1,636.09 \mathrm{~cm}^{-1}, 1,600 \mathrm{~cm}^{-1}$, and $1,285.49 \mathrm{~cm}^{-1}$. The prepared matrix tablet exhibited peaks at $3,504.38 \mathrm{~cm}^{-1}, 3,399.20$ $\mathrm{cm}^{-1}, 3,341.65 \mathrm{~cm}^{-1}, 1,057.71 \mathrm{~cm}^{-1}$, and $1,031.10 \mathrm{~cm}^{-1}$. No new peaks were detected in the tablet spectrum, indicating that no chemical changes had occurred between ingredients during the tablet preparation. Figure 6 shows the FTIR spectrum of pure crushed tablet, polymer, and famotidine.

\section{X-ray diffraction analysis of optimum} formulation (S5)

XRD is a rapid analytical technique, primarily used for phase identification of a crystalline material, and can provide information on unit cell dimensions. The X-ray diffractograms of pure drug, salep, and their respective formulation (S5) are shown in Figure 7. The X-ray diffractogram of pure famotidine showed sharp characteristic peaks at $5.15,11.6,17.65,22.55,25.55,26.5,30.55,32.7$, $35.55,37.6,39.7$, and 41.25 angles $\left({ }^{\circ} 2 \theta\right)$ indicating the crystallinity of the drug. Salep showed broad peaks at 16.55 and 20.55 angles $\left({ }^{\circ} 2 \theta\right)$, indicating the amorphous nature of the polymer. In the X-ray diffractogram of the optimum formulation, there was a decrease in crystallinity of the pure drug, as reflected in the diffractogram by a decrease in the intensity of the characteristic peaks. However, there were no major missing peaks in the formulation. Thus, the slight differences observed in the XRD patterns may be attributed to physical interactions as a result of compression during tableting, and due to dispersion of polymers while mixing.

\section{Microbial load and stability of the salep powder and S5 formulation}

The microbial limit of salep powder and the optimized formulation (S5) (stored at room temperature for 5 months) was found to be within the acceptance limit. Salep does

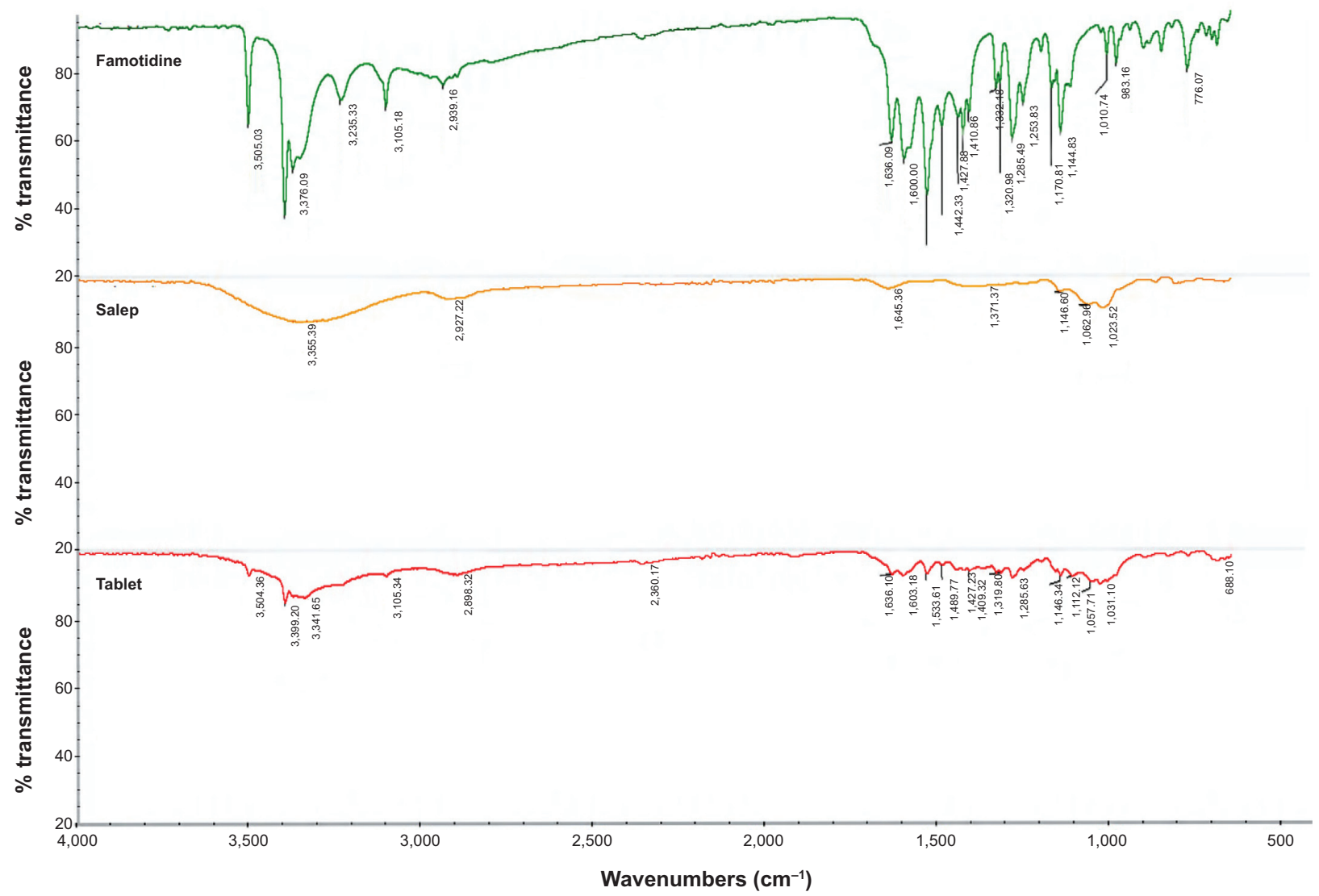

Figure 6 Fourier transform infrared spectroscopy of pure famotidine, pure salep powder, and crushed tablets of optimum formulation (S5). 
Table 4 Comparison of regression coefficients of drug release kinetics for Hixson-Crowell, Higuchi, First order, and Zero order models

\begin{tabular}{lllll}
\hline Formulation & Zero order & First order & Hixson-Crowell & Higuchi \\
\hline SI & $0.7368 \pm 2.67$ & $0.9518 \pm 1.02$ & $0.9110 \pm 4.87$ & $0.8366 \pm 3.57$ \\
S2 & $0.8185 \pm 2.87$ & $0.9460 \pm 0.9$ & $0.9099 \pm 3.89$ & $0.9066 \pm 3.06$ \\
S3 & $0.9970 \pm 3.02$ & $0.8763 \pm 2.09$ & $0.8723 \pm 2.76$ & $0.9633 \pm 2.97$ \\
S4 & $0.9869 \pm 2.90$ & $0.8579 \pm 2.78$ & $0.8619 \pm 2.47$ & $0.9654 \pm 3.09$ \\
S5 & $0.9746 \pm 2.09$ & $0.8549 \pm 2.37$ & $0.8596 \pm 2.06$ & $0.9428 \pm 4.57$ \\
S6 & $0.9838 \pm 1.97$ & $0.8876 \pm 3.90$ & $0.9518 \pm 3.72$ & $0.965 \pm 4.09$ \\
S7 & $0.9889 \pm 1.68$ & $0.8876 \pm 4.1$ & $0.9407 \pm 4.06$ & $0.9591 \pm 2.11$ \\
S8 & $0.9894 \pm 2.09$ & $0.8837 \pm 1.96$ & $0.9481 \pm 3.58$ & $0.9528 \pm 2.37$ \\
S9 & $0.9924 \pm 2.84$ & $0.8988 \pm 2.97$ & $0.9313 \pm 1.05$ & $0.9580 \pm 3.12$ \\
S10 & $0.9899 \pm 3.27$ & $0.8820 \pm 4.98$ & $0.9196 \pm 1.84$ & $0.9370 \pm 3.42$ \\
\hline Note & & &
\end{tabular}

Note: Results are shown as mean \pm standard deviation.

not support microbial growth, and the microbes are within the acceptable range. The results are shown in Table 5 . The stability test was done for the S5 formulation. The formulations were stored at $25^{\circ} \mathrm{C} \pm 2^{\circ} \mathrm{C}$ at $75 \% \pm 5 \%$ relative humidity for 5 months. The dissolution test was done, and the profile was compared to its original profile. The similarity factor $\left(f_{2}\right)$ was calculated, and its value was found to be 80 . Hence, the drug release is considered similar and it can be concluded that the prepared formulations were stable.

\section{In-vitro dissolution study of famotidine matrix tablets}

The percentage of drug release was measured for all the formulations. The results show that S1 released $70.96 \%$ of the drug within 1 hour. This formulation contained a low concentration of salep (10 mg), as shown in Figure 9.
However, the remaining $30 \%$ of the drug released slowly within 24 hours. This might be explained due to the time taken by salep to swell enough and control the release. The S2 formulation, released $56.53 \%$ of the drug in 1 hour, and the remaining quantity of drug released slowly in 24 hours. Hence, the concentration of the salep powder was increased in order for batches S3 to S10 to achieve the desired release profile. The result indicated matrix integrity, swelling, ability of the tablet to remain intact for more than 24 hours, and the release of the drug in a controlled manner for S3-S10 formulations, with $101.53 \%, 100.96 \%, 100.38 \%, 98.07 \%$, $97.5 \%, 97.5 \%, 96.34 \%$, and $96.34 \%$, respectively. The S5 formulation gave the best results, in terms of floating behavior, with a floating lag time of $38 \pm 0.42$ seconds, floating duration of more than 24 hours, and drug release sustained for 24 hours. From batches S3-S10, by increasing the polymer concentration, the release was decreased,

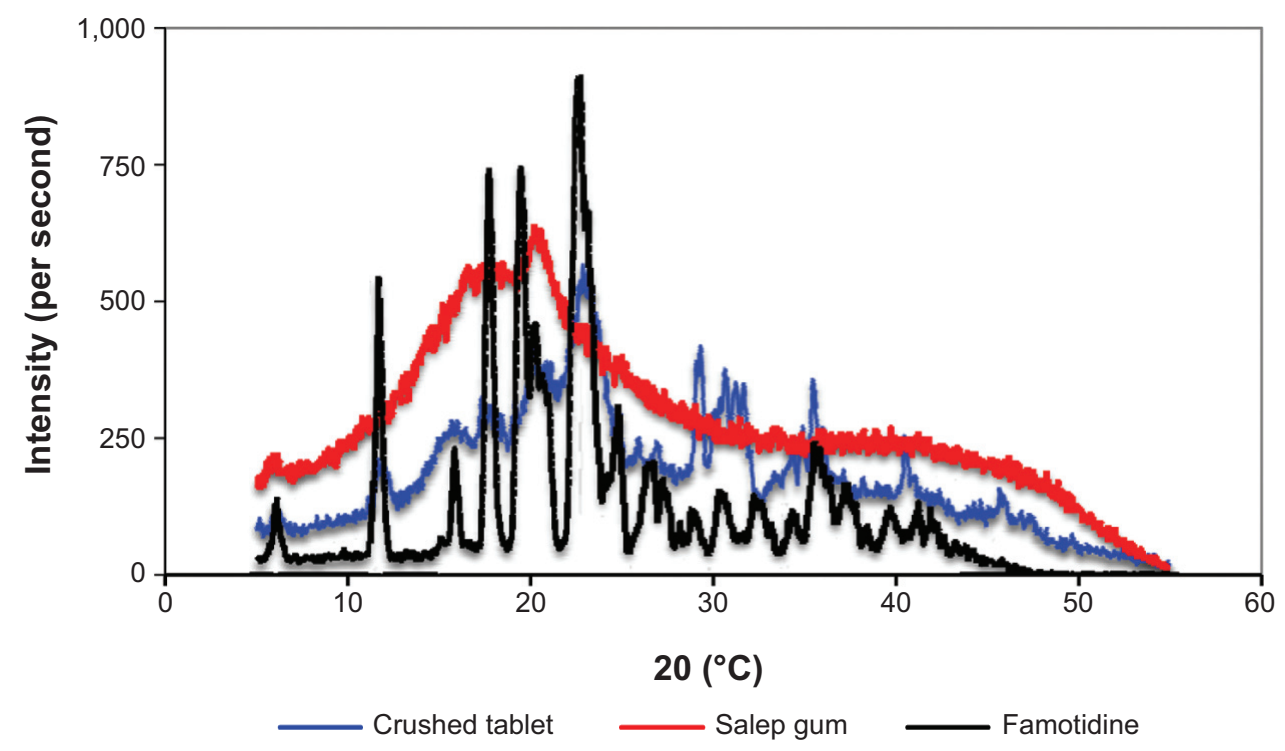

Figure 7 X-ray diffraction of pure famotidine, pure salep powder, and crushed tablet of optimum formulation (S5). 
Table 5 Microbial load of formulation and salep samples before and after storage

\begin{tabular}{lll}
\hline Microbiological quality & Before $\mathbf{5}$ months & After $\mathbf{5}$ months \\
\hline Total aerobic microbial count for salep & Less than $10^{3} \mathrm{CFU} / \mathrm{g}$ & Less than $10^{3} \mathrm{CFU} / \mathrm{g}$ \\
Total aerobic microbial count for tablet (S5) & Less than $10^{3} \mathrm{CFU} / \mathrm{g}$ & Less than $10^{3} \mathrm{CFU} / \mathrm{g}$ \\
Total combined yeasts/molds count for salep & Less than $10^{2} \mathrm{CFU} / \mathrm{g}$ & Less than $10^{2} \mathrm{CFU} / \mathrm{g}$ \\
Total combined yeasts/molds count for tablet (S5) & Less than $10^{2} \mathrm{CFU} / \mathrm{g}$ & Less than $10^{2} \mathrm{CFU} / \mathrm{g}$ \\
\hline
\end{tabular}

Abbreviation: CFU, colony-forming unit.

but the drug release profile proved that a salep:famotidine ratio of $1.5: 1$ or more is able to sustain drug release with the best swelling, intactness, and an optimum floating lag time of less than 15 minutes. Batches S8-S10 showed greater retardation of drug release, because of the higher concentration of polymer. A dissolution test was also done at $\mathrm{pH} 4.5$, and the results showed that only $80 \%$ of the active ingredient was released in 24 hours. This can be explained due to the high viscosity of salep at this $\mathrm{pH}$, compared against $\mathrm{pH}$ 1.2. An adhesive, thick, viscous barrier of swollen matrix was formed and, due to its high viscosity, carbon dioxide was either not generated or was trapped in the matrix layer, and the formulation failed to float at this $\mathrm{pH}$. This is in accordance with the viscosity and swelling studies.

\section{Drug release kinetics}

The kinetic data in Table 4 show the Zero-order, First order, Higuchi, and Hixson-Crowell model data of each formulation. When the highest correlation coefficient values are considered, the release data of formulations seem to fit better with the Zero order and Higuchi models, as is evident in Table 4. The highest value of the correlation coefficient for the S5 formulation was fitted to Zero order $(R=0.9746)$ and Higuchi $\left(R^{2}=0.9428\right)$ models. Drug release kinetics in all the formulations, except $\mathrm{S} 1$ and $\mathrm{S} 2$, had a higher linearity of Zero order kinetic plot, compared against the First order kinetic plot. This indicates the rate of release is independent of concentration, and is constant over time. Zero order, or constant rate of release of drug, is desirable in order to minimize the changes of drug concentration in the blood. This can prolong the release and maintain drug concentration within the therapeutic range for a longer period of time, and can minimize the risk of toxicity. ${ }^{43}$

Higuchi was the dominant drug release mechanism for all the formulations, except S1 and S2, because the Higuchi plot had higher linearity, compared against the Hixson-Crowell. The result indicated that drug release characteristics from the polymer matrix tablets follow Higuchi diffusion and relaxation. This was likely due to the strong matrix formed from a high proportion of polymer, with limited cap space, which resulted in limited drug release by diffusion. ${ }^{44}$

\section{S2-S10 formulations after 24 hours dissolution test}

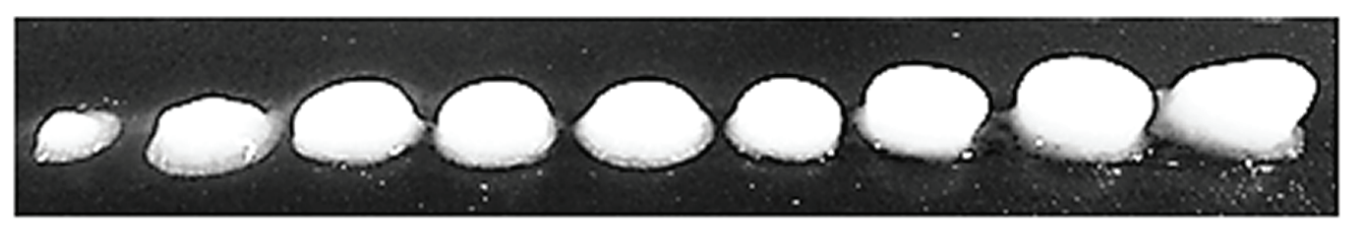

The optimum formulation (S5) before and after 24 hours dissolution test

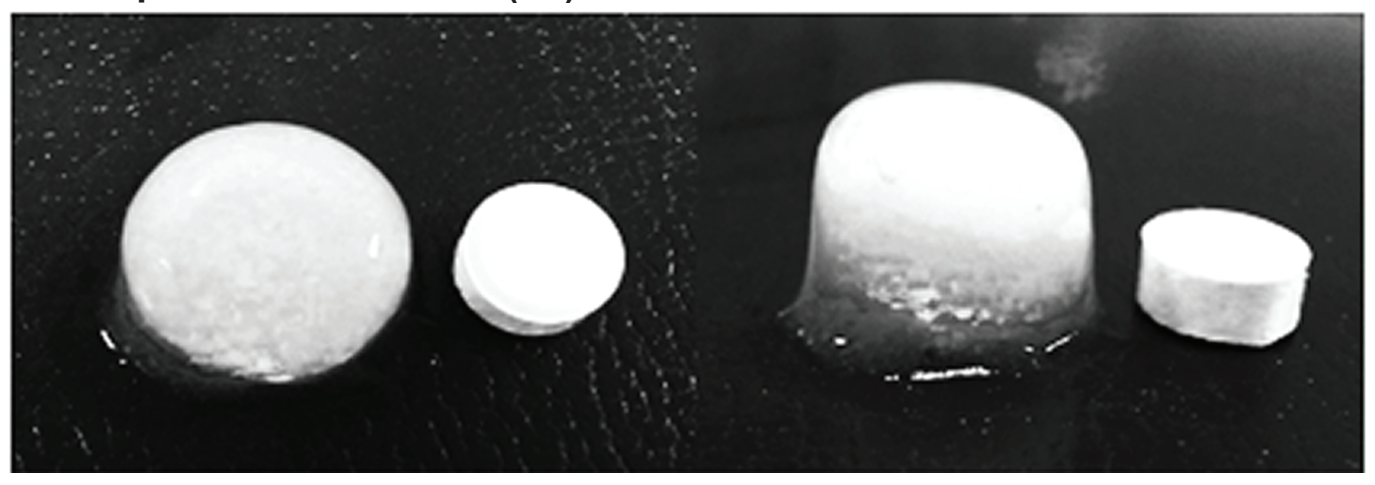

Figure $\mathbf{8}$ The shape of famotidine matrix tablets after in vitro dissolution test. Note: The bottom image shows the tablet before (left) and after the test (right). 


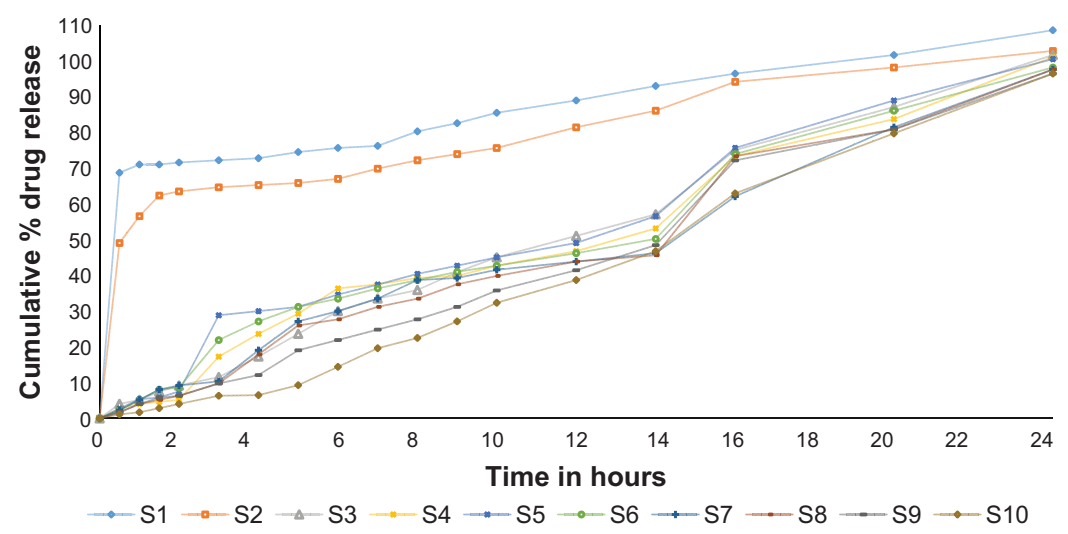

Figure 9 Drug release profiles of gastroretentive matrix tablets of famotidine in 24-hour in vitro study.

\section{Conclusion}

The present research proposed a novel formulation using salep, a new hydrogel and swellable polymer, to develop a gastroretentive matrix tablet. Investigation of the preparation, characterisation, and in vitro release of the floating matrix tablet was carried out. The different formulations, with various ratios of salep as hydrogel, were evaluated and optimized. The results demonstrated that salep could be an efficient hydrogel for drug delivery, which can achieve a retarding effect in a controlled release system. Salep was used successfully in this study to formulate a hydrodynamically balanced matrix system of famotidine, which is of gastroretentive character. The optimum formulation S5 had excellent buoyancy, with complete drug release in 24 hours.

\section{Acknowledgment}

The authors gratefully acknowledge the generous financial support from the University of Malaya, the HIR research grant (UM-MOHE UM.C/625/1/HIR/MOHE/SC/09) and IPPP research grant (PG052/2012B) in providing funding to perform this study.

\section{Disclosure}

The authors declare no conflicts of interest in this work.

\section{References}

1. Crowley PJ, Martini LG. Excipients for pharmaceutical dosage forms. In: Swarbrick J, Boylan JC, eds. Encyclopedia of Pharmaceutical Technology. 2nd ed. New York: Marcel Dekker; 2002:p.1151.

2. Patel H, Shah V, Upadhyay U. New pharmaceutical excipients in solid dosage forms-a review. Int J Pharm Life Sci. 2011;2(8):1006-1019.

3. Friend DR, Geoffroy JM, Ng S, Sarabia RE, Weber TP. Taste-masked microcapsule compositions and methods of manufacture. United States Patent US6139865 A; 2000.

4. Garg R, Gupta G. Progress in controlled gastroretentive delivery systems. Trop J Pharm Res. 2008;7(3):1055-1066.
5. Ulbrich K, Šubr V, Strohalm J, Plocová D, Jelınková M, Říhová B. Polymeric drugs based on conjugates of synthetic and natural macromolecules: I. Synthesis and physico-chemical characterisation. J Control Release. 2000;64(1):63-79.

6. Scott G. 'Green' polymers'. Polym Degrad Stabil. 2000;68(1):1-7.

7. Bhardwaj TR, Kanwar M, Lal R, Gupta A. Natural gums and modified natural gums as sustained-release carriers. Drug Dev Ind Pharm. 2000;26(10):1025-1038.

8. Prajapati VD, Jani GK, Moradiya NG, Randeria NP. Pharmaceutical applications of various natural gums, mucilages and their modified forms. Carbohydr polym. 2013;92(2):1685-1699.

9. Jani GK, Shah DP, Prajapati VD, Jain VC. Gums and mucilages: versatile excipients for pharmaceutical formulations. Asian J Pharm Sci. 2009;4(5):309-323.

10. Sharma VK, Mazumdar B. Feasibility and characterization of gummy exudate of Cochlospermum religiosum as pharmaceutical excipient. Ind Crop Prod. 2013;50:776-786.

11. Jani GK, Shah DP, Jain VC, Patel MJ, Vithalani DA. Evaluating mucilage from Aloe barbadensis Miller as a pharmaceutical excipient for sustained-release matrix tablets. Pharm Tech. 2007;31(11):90.

12. Karaman S, Kayacier A. Rheological characteristics of traditional salep drink flavored with cocoa powder. GIDA. 2010;35(6):397.

13. Hossain MM. Therapeutic orchids: traditional uses and recent advances - an overview. Fitoterapia. 2011;82(2):102-140.

14. Farhoosh R, Riazi A. A compositional study on two current types of salep in Iran and their rheological properties as a function of concentration and temperature. Food Hydrocolloid. 2007;21(4):660-666.

15. Allimuthu M, Walter TM. The role of salamisri (Orchis mascula) in geriatric care. Openmed [Internet]. 2008;1(9):LR1-LR9.

16. Kaya S, Tekin AR. The effect of salep content on the rheological characteristics of a typical ice-cream mix. J Food Eng. 2001;47(1):59-62.

17. Pourjavadi A, Soleyman R, Barajee GR. Novel nanoporous superabsorbent hydrogel based on poly (acrylic acid) grafted onto salep: synthesis and swelling behavior. Starch-Starke. 2008;60(9):467-475.

18. Pourjavadi A, Bardajee GR, Soleyman R. Synthesis and swelling behavior of a new superabsorbent hydrogel network based on polyacrylamide grafted onto salep. J Appl Polym Sci. 2009;112(5):2625-2633.

19. Georgiadis N, Ritzoulis C, Charchari E, Koukiotis C, Tsioptsias C, Vasiliadou C. Isolation, characterization and emulsion stabilizing properties of polysaccharides form orchid roots (salep). Food Hydrocolloid. 2012;28(1):68-74.

20. Tang OS, Schweer H, Seyberth H, Lee SW, Ho PC. Pharmacokinetics of different routes of administration of misoprostol. Hum Reprod. 2002;17(2):332-336.

21. Agoram B, Woltosz WS, Bolger MB. Predicting the impact of physiological and biochemical processes on oral drug bioavailability. $A d v$ Drug Deliv Rev. 2001;50 Suppl 1:S41-S67. 
22. Deshpande A, Rhodes C, Shah N, Malick A. Controlled-release drug delivery systems for prolonged gastric residence: an overview. Drug Dev Ind Pharm. 1996;22(6):531-539.

23. Dehghan M, Kha F. Gastroretentive drug delivery systems: a patient perspective. Int J Health Res. 2009;2(1):23-44.

24. Singh BN, Kim KH. Floating drug delivery systems: an approach to oral controlled drug delivery via gastric retention. J Control Release. 2000;63(3):235-259.

25. Kajale AD, Chandewar AV. Recent advances in gastro retentive drug delivery system - a review. Indo Amer J Pharm Res. 2013;3(7): 5221-5232.

26. Arora S, Ali J, Ahuja A, Khar RK, Baboota S. Floating drug delivery systems: a review. AAPS Pharm Sci Tech. 2005;6(3):E372-E390.

27. Dave BS, Amin AF, Patel MM. Gastroretentive drug delivery system of ranitidine hydrochloride: formulation and in vitro evaluation. AAPS Pharm Sci Tech. 2004;5(2):e34.

28. Weh FH, Razavi M, Erh CH, et al. Formulation and in vitro evaluation of hydrodynamically balanced matrix tablets of famotidine using pectin as controlled release polymer. Lat Am J Pharm. 2014;33(3):11.

29. Badawy SIF, Menning MM, Gorko MA, Gilbert DL. Effect of process parameters on compressibility of granulation manufactured in a highshear mixer. Int J Pharm. 2000;198(1):51-61.

30. Jaimini M, Rana A, Tanwar Y. Formulation and evaluation of famotidine floating tablets. Curr Drug Deliv. 2007;4(1):51-55.

31. Murali Mohan Babu GV, Prasad ChD, Ramana Murthy KV. Evaluation of modified gum karaya as carrier for the dissolution enhancement of poorly water-soluble drug nimodipine. Int J Pharm. 2002; 234(1-2):1-17.

32. Mandal S, Basu SK, Sa B. Sustained release of a water-soluble drug from alginate matrix tablets prepared by wet granulation method. AAPS Pharm Sci Tech. 2009;10(4):1348-1356.

33. Bomma R, Swamy Naidu RA, Yamsani MR, Veerabrahma K. Development and evaluation of gastroretentive norfloxacin floating tablets. Acta Pharm. 2009;59(2):211-221.
34. Paul Y, Kumar M, Singh B. Formulation, evaluation and study of effect of hydrophilic polymers on release rate of cefixime floating tablets. Int J Pharma Bio Sci. 2011;2(4):472-488.

35. The United States Pharmacopeial Convention. The 2007 United States Pharmacopeia 30 - National Formulary 25. Rockville, MD: The United States Pharmacopeial Convention, Inc. 2008;61:83.

36. Dash S, Murthy PN, Nath L, Chowdhury P. Kinetic modeling on drug release from controlled drug delivery systems. Acta Pol Pharm. 2010; 67(3):217-223.

37. Siepmann J, Siepmann F. Mathematical modeling of drug delivery. Int J Pharm. 2008;364(2):328-343.

38. Abdullah E, Geldart D. The use of bulk density measurements as flowability indicators. Powder Technol. 1999;102(2):151-165.

39. Fitzpatrick S, McCabe JF, Petts CR, Booth SW. Effect of moisture on polyvinylpyrrolidone in accelerated stability testing. Int J Pharm. 2002; 246(1-2):143-151.

40. Lee CY, Chen GL, Sheu MT, Liu CH. Drug release from hydroxypropyl cellulose and polyethylene oxide capsules: in vitro and in vivo assessment. Chin Pharm J. 2006;58(1):57-65.

41. Jiménez-Martínez I, Quirino-Barreda T, Villafuerte-Robles L. Sustained delivery of captopril from floating matrix tablets. Int J Pharm. 2008; 362(1-2):37-43.

42. Chen YC, Ho HO, Lee TY, Sheu MT. Physical characterizations and sustained release profiling of gastroretentive drug delivery systems with improved floating and swelling capabilities. Int J Pharm. 2013; 441(1):162-169.

43. Siegel RA, Rathbone MJ. Overview of controlled release mechanisms In: Siepmann J, Siegel RA, Rathbone MJ, eds. Fundamentals and applications of controlled release drug delivery. New York: Springer; 2012. p.19-43.

44. Siepmann J, Siegel RA, Siepmann F. Diffusion controlled drug delivery systems. In: Siepmann J, Siegel RA, Rathbone MJ, eds. Fundamentals and applications of controlled release drug delivery: New York: Springer; 2012. p.127-152.

\section{Publish your work in this journal}

Drug Design, Development and Therapy is an international, peerreviewed open-access journal that spans the spectrum of drug design and development through to clinical applications. Clinical outcomes, patient safety, and programs for the development and effective, safe, and sustained use of medicines are a feature of the journal, which

\section{Dovepress}

has also been accepted for indexing on PubMed Central. The manuscript management system is completely online and includes a very quick and fair peer-review system, which is all easy to use. Visit http://www.dovepress.com/testimonials.php to read real quotes from published authors. 